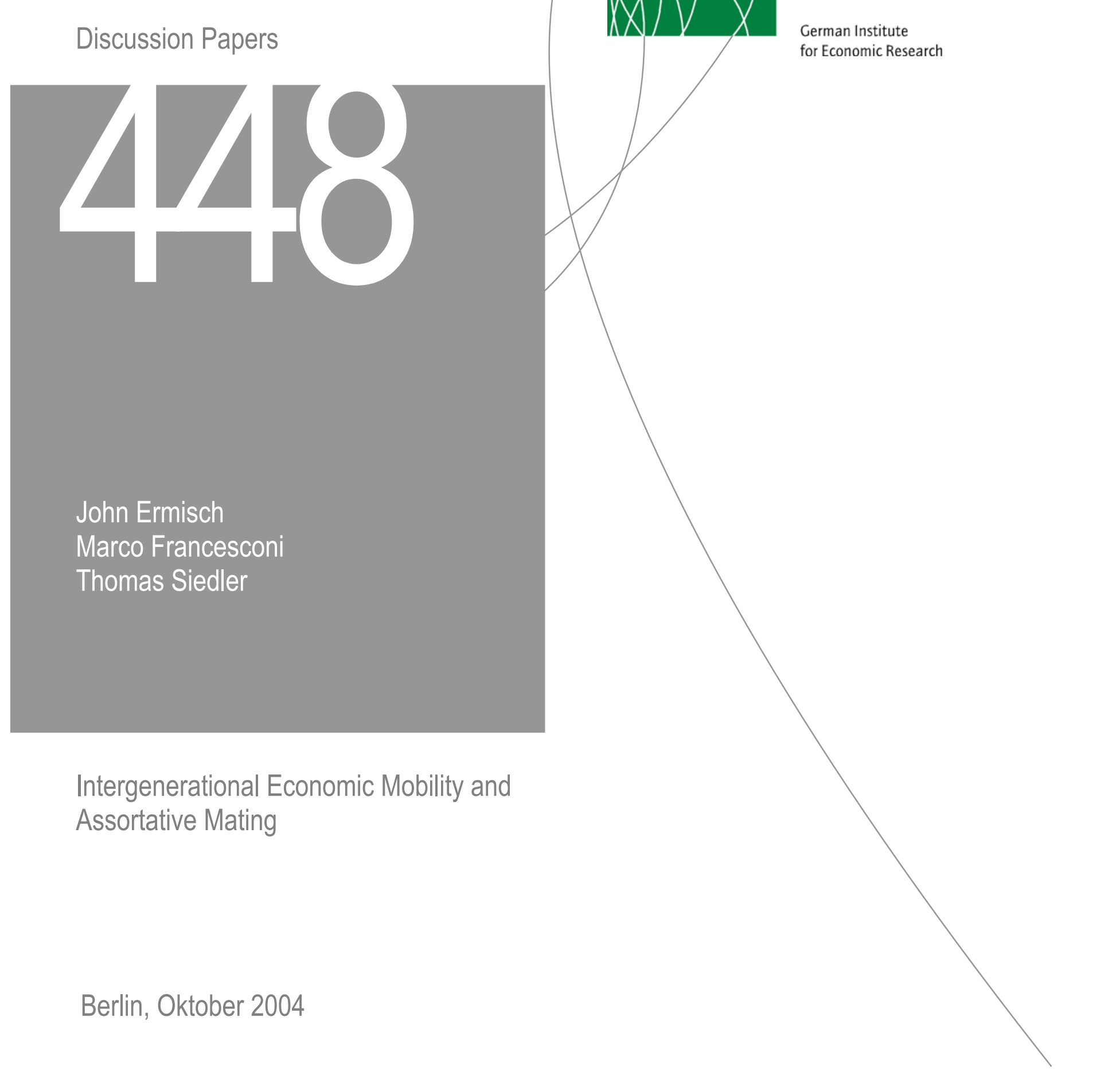


Opinions expressed in this paper are those of the author and do not necessarily reflect views of the Institute.

DIW Berlin

German Institute

for Economic Research

Königin-Luise-Str. 5

14195 Berlin,

Germany

Phone $+49-30-89789-0$

Fax $\quad+49-30-89789-200$

www.diw.de

ISSN 1619-4535 


\title{
Intergenerational Economic Mobility and Assortative Mating *
}

\author{
John Ermisch \\ Institute for Social and \\ Economic Research \\ University of Essex
}

\author{
Marco Francesconi \\ Department of Economics \\ University of Essex
}

\author{
Thomas Siedler \\ Institute for Social and \\ Economic Research \\ University of Essex \\ and DIW Berlin
}

\begin{abstract}
We use data from the German Socio-Economic Panel and the British Household Panel Survey to estimate the extent of intergenerational economic mobility in a framework that highlights the role played by assortative mating. We find that assortative mating plays an important role. On average about 40-50 percent of the covariance between parents' and own permanent family income can be attributed to the person to whom one is married. This effect is driven by strong spouse correlations in human capital.
\end{abstract}

September 2004

JEL Classification: J12, I20, D31, D64

Keywords: Intergenerational links, marriage market, assortative mating, occupational prestige

\footnotetext{
* Correspondence to: John Ermisch, Institute for Social and Economic Research, University of Essex, Colchester CO4 3SQ, United Kingdom (ermij@essex.ac.uk). Support for this research from the Economic and Social Research Council is gratefully acknowledged. We thank Anders Björklund, Nick Buck, Miles Corak, Muriel Egerton, Nathan Grawe, Stephen Jenkins, Sandy Jenks, Dave Maré, Cheti Nicoletti, Lars Osberg, Erik Plug, Gary Solon, Rudolf Winter-Ebmer and seminar participants at the University of Essex, IZA (Bonn), Tinbergen Institute (Amsterdam), the 2001 Workshop on Intergenerational Mobility at Statistics Canada (Ottawa), the 2001 ESPE conference (Athens) and two referees for their helpful comments and suggestions on previous drafts of this work.
} 
Most of what we know about how socio-economic status is passed from one generation to the next comes from studies of fathers and sons, or, more rarely, fathers and daughters. ${ }^{1}$ But those sons and daughters usually become someone's spouse, and the way in which this matching occurs may have consequences for their own socio-economic position. Accordingly, how inequality evolves over generations depends on more than just one's own labour income or human capital, it depends on who marries whom. Thus, both parents and parents-in-law shape their offspring's status. This paper's main contribution is to estimate the extent to which assortative mating affects intergenerational economic mobility in Germany and Britain, following the suggestion by Chadwick and Solon (2002, p.343) that replication of their results using data from other countries would be particularly informative. The paper also makes a methodological contribution in demonstrating that retrospective information on father's occupation, summarised in an "occupational prestige" score that is correlated with earnings, can be used to obtain estimates of intergenerational mobility that are comparable to those obtained from direct information on earnings.

For centuries and in several countries, marriage has been one of the primary institutions through which economic mobility and social stratification took place (Hamilton, 1912; Goody, 1983). The development of a national marriage market in London and Bath in the second half of the eighteenth century greatly widened the pool of potentially satisfactory spouses from the point of view of upper-class parents, because it increased the number of potential spouses who would meet the necessary financial and social qualifications (Stone, 1977). Two centuries later, for a group of working-class families sampled in London between 1943 and 1946, Slater and Woodside (1951) report high and significant correlation coefficients between husbands and wives on a number of characteristics, including age at

\footnotetext{
${ }^{1}$ The majority of studies in this literature focus on fathers. See Solon (1999) for a detailed survey. Presumably the neglect of mothers has stemmed from the recognition that, in societies in which married women's labour force participation rates are lower than men's, women's earnings (and incomes) are likely to be an unreliable measure of their status. Important exceptions are Thomas (1994), Couch and Dunn (1997), Dearden et al. (1997) and Chadwick and Solon (2002).
} 
marriage, stature, social background and pre-marital sex experience. ${ }^{2}$ Thus, there is evidence of purposeful mating that is likely to affect the correlation between one's own socio-economic position and that of their parents.

One of the few economic studies that explicitly recognises the link between assortative mating and intergenerational mobility is that by Chadwick and Solon (2002), which further develops the earlier works by Lam and Schoeni $(1993,1994)$. Chadwick and Solon find that assortative mating plays a key role in the intergenerational transmission process in the United States. In particular, “spouses' earnings appear to be just as elastic as the offspring's own earnings with respect to the parents' income" (Chadwick and Solon, p. 343). Lam and Schoeni (1994) interpret the greater effect of father-in-law's schooling than that of father's schooling on the wages of male workers in Brazil as an indication of a high degree of assortative mating in the marriage market. ${ }^{3}$ This paper is in a similar vein. It derives intergenerational links between own income and parents' income and partner's income and parents' income using utility-maximising behaviour by parents in the spirit of the studies carried out by Becker and Tomes (1979, 1986), Loury (1981) and Mulligan (1999). ${ }^{4}$

We use two sources of data: the German Socio-Economic Panel (SOEP) and the British Household Panel Survey (BHPS). The former has sufficient information on earnings of parents and their offspring to estimate our model using a standard earnings' measure of economic status, and with these data we also replicate Chadwick and Solon's approach for Germany. For Britain, we must use a non-standard measure of economic status based on an "occupational prestige" score, but because we also have a similar such measure for Germany

\footnotetext{
${ }^{2}$ Epstein and Guttman (1984) provide a comprehensive overview of several (noneconomic) studies on assortative mating. For more recent analyses, see Mare (1991) and Kalmjin (1994).

${ }^{3}$ Using a sample of father-child pairs with fathers coming from the 1950 Rowntree inquiry in York (England) and children subsequently traced in the late 1970s, Atkinson et al. (1983) find that the elasticity of male earnings with respect to father-in-law's earnings is similar to the elasticity of male earnings with respect to own father's earnings. A similar result is found for Malaysia by Lillard and Kilburn (1995).

${ }^{4}$ For an interesting discussion on mechanical versus optimising models, see the exchange of opinions between Goldberger (1989) and Becker (1989). See also Mulligan (1999).
} 
we are able to compare the results with those using earnings. We present a measurement model that shows the conditions under which our estimates are consistent estimates of the parameters in our model. In the next section, we present a simple model that illustrates the potential importance of assortative mating in the intergenerational transmission of socioeconomic status. Section 2 presents our measurement model and assesses the main properties of our estimators. Section 3 describes the data, while Section 4 discusses our econometric methods. The empirical results in Section 5 show that assortative mating is an important element in the intergenerational transmission process, and its contribution is similar irrespective of economic status measure or country. Section 6 concludes.

\section{Assortative mating and intergenerational links}

The framework motivating this study integrates assortative mating considerations into a simple model of human capital investments in children. Besides their own consumption, $C_{t-1}$, parents are assumed to care about the expected joint "permanent" income of their adult offspring, which is the expected sum of their child's and his/her future partner's permanent incomes, $E\left[y_{t}+y_{t}^{p}\right]$, where $t$ indicates the generation, $p$ indicates the partner and $E[$.$] is the$ expectations operator. ${ }^{5}$ As mentioned above, a considerable body of research has shown that there is systematic (or nonrandom) positive sorting of partners with respect to complementary characteristics, non-wage incomes and possibly wages (e.g., Becker, 1991; Lam, 1988; Lam and Schoeni, 1994). This leads us to specify the following matching function

$$
H_{t}^{p}=\alpha_{0}+\alpha_{1} H_{t}+v_{t}^{p}
$$

which links own and potential partner's "human capital", denoted by $H_{t}$ and $H_{t}^{p}$, respectively. The stochastic term $v_{t}^{p}$ includes other (unobserved) factors relevant for mate

\footnotetext{
${ }^{5}$ For convenience the terms "partner" and "spouse" (husband or wife) are synonymous here.
} 
selection, such as attractiveness and tastes (Kalmijn, 1994), whereas the parameter $\alpha_{1}$ captures the degree of assortative mating with respect to human capital. Although assortative mating is in reality more complex than what equation (1) implies, this formulation is very similar to those adopted in Lam and Schoeni (1993, 1994) and Chadwick and Solon (2002). The difference is that those studies assume that marital sorting is with respect to earnings or incomes, while here it is on human capital.

Individual permanent incomes are assumed to increase with human capital:

$$
\begin{aligned}
& y_{t}=\gamma_{01}+\gamma_{1} H_{t}+e_{t} \\
& y_{t}^{p}=\gamma_{02}+\gamma_{2} H_{t}^{p}+e_{t}^{p},
\end{aligned}
$$

where $\gamma_{1}$ and $\gamma_{2}$ are nonnegative parameters, and the stochastic terms $e_{t}$ and $e_{t}^{p}$ are independent of one another and of $v_{t}^{p}$. These income equations allow the returns to human capital to differ between the sexes.

The parents' consensus utility is given by $U=\pi \log \left(E\left[y_{t}+y_{t}^{p}\right]\right)+(1-\pi) \log \left(C_{t-1}\right)$, with $\pi \in(0,1)$ measuring the relative preference for child's future family income as against parents' own consumption. Parents choose $H_{t}$ to maximise their utility subject to (1)-(3) and their budget constraint, $y_{t-1}=C_{t-1}+p_{H} H_{t}$, where $p_{H}$ is the relative unit price of child's human capital. ${ }^{6}$ The solution to this problem implies that the optimal level of child's human capital is a linear function of parents' income, with slope $\pi / p_{H}$. Using this expression and (2), the income of the child becomes

$$
y_{t}=\beta_{0}+\beta_{1} y_{t-1}+u_{1 t}
$$

\footnotetext{
${ }^{6}$ Consensus parental utility entails that human capital investment depends on total family income, $y_{t-1}$; it does not depend differentially on mothers' and fathers' incomes, as would be the case when outcomes emerge from intrafamily bargaining, and personal incomes affect bargaining power.
} 
where $\beta_{1}=\pi \gamma_{1} / p_{H}$, and $u_{1 t}$ is a stochastic term that depends on $v_{t}^{p}, e_{t}$ and $e_{t}^{p}$. Using (1) and (3), the partner's income is given by

$$
y_{t}^{p}=\delta_{0}+\delta_{1} y_{t-1}+u_{2 t},
$$

where $\delta_{1}=\alpha_{1} \pi \gamma_{2} / p_{H}$, and $u_{2 t}$ is another stochastic term that depends on $v_{t}^{p}, e_{t}$ and $e_{t}^{p}$. Equations (4) and (5) form the basis of our empirical analysis, whose main focus is therefore on the reduced-form parameters $\beta_{1}$ and $\delta_{1}{ }^{7}$ From the definitions of such parameters in terms of their structural counterparts, it follows that $\delta_{1} / \beta_{1}=\alpha_{1} \gamma_{2} / \gamma_{1}$. If the income returns to human capital are the same for men and women $\left(\gamma_{1}=\gamma_{2}\right)$, then the ratio $\delta_{1} / \beta_{1}$ identifies $\alpha_{1}$, the degree of assortative mating on human capital in (1).

Finally the model has implications for the relationship between child's family income, $y_{t}+y_{t}^{p}$, and that of his/her parents, whereby

$$
\operatorname{cov}\left(y_{t}+y_{t}^{p}, y_{t-1}\right)=\operatorname{cov}\left(y_{t}, y_{t-1}\right)+\operatorname{cov}\left(y_{t}^{p}, y_{t-1}\right)=\left(\beta_{1}+\delta_{1}\right) \operatorname{var}\left(y_{t-1}\right) .
$$

The contribution that assortative mating makes to the intergenerational mobility process is taken to be $\mu=\operatorname{cov}\left(y_{t}^{p}, y_{t-1}\right) / \operatorname{cov}\left(y_{t}+y_{t}^{p}, y_{t-1}\right)$, which in our context is given by

$$
\mu=\frac{\delta_{1}}{\delta_{1}+\beta_{1}}=\frac{\alpha_{1} \gamma_{2}}{\gamma_{1}+\alpha_{1} \gamma_{2}} .
$$

It is straightforward to see that $\mu$ decreases with $\beta_{1}$ and increases with $\delta_{1}$, and (7) implies that $\alpha_{1}=\gamma_{1} \mu /\left[(1-\mu) \gamma_{2}\right]$. Clearly if the income returns to human capital are the same for men and women, then $\alpha_{1}=\mu /(1-\mu)$.

\footnotetext{
${ }^{7}$ Notice that equations (4) and (5) are similar to equations (1) and (3) in Chadwick and Solon (2002), but the relationship between the two slope parameters is different—-see their equations (2) and (4).
} 


\section{Measurement issues}

Estimation of the reduced-form parameters $\beta_{1}$ and $\delta_{1}$ requires data that provide information on the socio-economic position of individuals, their partners and their parents. One of two data sources is the first nine waves of the British Household Panel Survey (BHPS) collected annually over the period 1991-1999. At present the panel is too short to relate the children's income as adults to the income of their parents as annually reported by the children and parents themselves. Fortunately, the BHPS asks respondents to provide information about their parents' occupations when they were aged 14, and releases data on an index of occupational prestige computed according to the technique proposed by Goldthorpe and Hope (1974). ${ }^{8}$ Matching partners in all available waves provides us with information for each partner's Hope-Goldthorpe (HG) scores and childhood information (at age 14) about parents' HG scores. ${ }^{9}$ The HG index ranges from 5 to 95 (and from 17 to 85 in our data), with greater values indicating higher occupational prestige, and it is highly correlated with earnings. ${ }^{10}$ The BHPS data indicate a correlation between gross monthly earnings and the HG index of 0.70 for men and 0.75 for women. In addition, because the position of individuals in the occupational hierarchy is relatively stable over time, the HG scale is also likely to be an adequate measure of people's permanent socio-economic status (Nickell, 1982). ${ }^{11}$

\footnotetext{
${ }^{8}$ Goldthorpe and Hope (1974) suggest that the scale which results from their occupational prestige grading exercise should not be viewed as a grading of social status stricto sensu, i.e., as tapping some underlying structure of social relations of "deference, acceptance and derogation" (p. 10). It should instead be viewed as "a judgement which is indicative of what might be called the 'general goodness' or ... the 'general desirability' of occupations" (pp. 11-12).

${ }_{9}$ The information on parents' occupation was collected only in waves 1, 8 and 9 (1991, 1998 and 1999 respectively).

${ }^{10}$ Phelps Brown (1977) reports a strong log-linear relationship between median gross weekly earnings and the HG score, with a rise of 1 unit in the index being associated with an increase of 1.031 percent in earnings. Nickell (1982) finds a correlation between the HG score and the average hourly earnings of 0.85 .

${ }^{11}$ To support this claim, we used the employment history file collected in the 1993 wave of the BHPS and obtained a measure of the HG scores at the time of permanent entry into the labour market for all respondents who provided full information at that wave. We then observed the HG scores for workers at the end of their careers (ages 56-65 for men and ages 55-60 for women) during the survey period (1991-99). We found that the correlation between an individual's position in the occupational hierarchy (as measured by the HG index) on entry into the labour market and at end of the working career was almost 0.60 for men and 0.62 for women, respectively, even after controlling for a large set of socio-demographic characteristics. Averaging the HG scores over age for each older worker produced similar, albeit slightly smaller, correlations.
} 
The other source of data is the German Socio-Economic Panel (SOEP) over the period 1984-2002. Like the BHPS, the SOEP too provides information on respondents' father's occupation when they were aged 15, and publishes an index of occupational prestige computed according to the technique proposed by Ganzeboom and Treiman (1996). The Treiman standard international occupational prestige score varies from 13 to 78 . Like the HG scale, larger values indicate higher occupational prestige, and it is highly correlated with earnings, although not as high as the HG scores in Britain; the correlation with gross monthly earnings in the SOEP is 0.39 for men and 0.43 for women.

To see how the permanent incomes of our theoretical model of Section 1 are related to the HG and Treiman indices, denoted $M_{t}$, we now specify a simple "measurement model". Suppose that the parents' permanent income, $y_{t-1}$, is a linear function of the father's index when the child was aged 14 (or 15), $M_{t-1}$, as follows: ${ }^{12}$

$$
y_{t-1}=a_{0}+a_{1} M_{t-1}+\varepsilon_{t-1}
$$

The child generation's permanent income is similarly defined as

$$
y_{t}^{j}=b_{0 j}+b_{1 j} M_{t}^{j}+\varepsilon_{t j}
$$

where $j=m, f$ denotes male and female children respectively. The stochastic terms $\varepsilon_{t-1}$ and $\varepsilon_{t j}$ are assumed to have zero means and to be independent of one another and of $M_{t-1}$ and $M_{t}^{j} \cdot{ }^{13}$

\footnotetext{
${ }^{12}$ In the model of Section 1, parents' decisions depend on the permanent income of the family (rather than that of the father). However, aggregating mother's and father's HG or Treiman scores will not yield a meaningful measure of family social status. We therefore chose to use the father's HG or Treiman index as a first approximation of parents' permanent income.

${ }^{13}$ The independence of $\varepsilon_{t-1}$ and $\varepsilon_{t j}$ may be a strong assumption if there is correlation in other factors affecting permanent income that are correlated between parents and their offspring. We address this possibility below.
} 
If for instance we look at sons, the estimates of $\beta_{1}$ and $\delta_{1}$ from the HG and Treiman scale data are, respectively, $\hat{\beta}_{1}=\frac{\operatorname{cov}\left(M_{t-1}, M_{t}^{m}\right)}{\operatorname{var}\left(M_{t-1}\right)}$ and $\hat{\delta}_{1}=\frac{\operatorname{cov}\left(M_{t-1}, M_{t}^{f}\right)}{\operatorname{var}\left(M_{t-1}\right)}$. Using the measurement model equations (8) and (9), it follows that

$$
p \lim \hat{\beta}_{1}=\beta_{1}\left[\frac{a_{1}}{b_{1 m}}\right]\left[\frac{\operatorname{var}\left(y_{t-1}\right)}{\operatorname{var}\left(y_{t-1}\right)+\operatorname{var}\left(\varepsilon_{t-1}\right)}\right]
$$

and

$$
p \lim \hat{\delta}_{1}=\delta_{1}\left[\frac{a_{1}}{b_{1 f}}\right]\left[\frac{\operatorname{var}\left(y_{t-1}\right)}{\operatorname{var}\left(y_{t-1}\right)+\operatorname{var}\left(\varepsilon_{t-1}\right)}\right]
$$

Thus, in general, we do not obtain consistent estimates of the reduced-form parameters $\beta_{1}$ and $\delta_{1}$. Whether or not they are biased downward, as in the classical measurement error model, depends on the magnitude of $\operatorname{var}\left(\varepsilon_{t-1}\right)$ and on the ratio $a_{1} / b_{1 j}$. If this ratio is less than unity, they are certainly biased downward; if instead it is greater than one, then $\hat{\beta}_{1}$ and $\hat{\delta}_{1}$ may be biased upward or downward. But our estimate of $\hat{\mu}=\frac{\hat{\delta}_{1}}{\hat{\delta}_{1}+\hat{\beta}_{1}}$ has the following property:

$$
p \lim \hat{\mu}=\frac{\delta_{1}}{\left(b_{1 f} / b_{1 m}\right) \beta_{1}+\delta_{1}} .
$$

If the measurement links between permanent income and the $M_{t}$ index are the same for men and women $\left(b_{1 m}=b_{1 f}\right)$, then we obtain a consistent estimate of $\mu$. Suppose, however, that the measurement errors for parents and sons are positively correlated, that is $\operatorname{cov}\left(\varepsilon_{t-1}, \varepsilon_{t m}\right)>0$, and let $\varphi$ define $\operatorname{cov}\left(\varepsilon_{t-1}, \varepsilon_{t m}\right) / \operatorname{var}\left(y_{t-1}\right)$. This implies that the denominator of equation (12) also contains an additional term, $\left(b_{1 f} / b_{1 m}\right) \varphi$, and our estimate of $\mu$ tends to be downward biased. Finally, if the income returns to human capital are the same for men and women 
$\left(\gamma_{1}=\gamma_{2}\right)$, then, defining $\hat{\alpha}_{1}=\frac{\hat{\delta}_{1}}{\hat{\beta}_{1}}, p \lim \hat{\alpha}_{1}=\frac{b_{1 m} \delta_{1}}{b_{1 f} \beta_{1}}$. Thus, $\alpha_{1}$ is also identified under these conditions if $b_{1 m}=b_{1 f}$.

There are, however, three further measurement problems with the occupational prestige measure: (a) we only have one observation on $M_{t-1}$ (when the child was aged 14 or 15); (b) the data on parents are obtained from adult children, and not from the parents themselves; and (c) a misclassification error may arise when a new occupation is observed or an old occupation disappears. ${ }^{14}$ By diminishing the signal proportion of the sample variation in measured $M$ scores, these problems are likely to induce another downward error-invariables bias in the estimates of both $\beta_{1}$ and $\delta_{1}$, in addition to the inconsistency suggested by equations (10) and (11). But to the extent that such a bias affects both parameters similarly, the estimation of their ratio as well as $\mu$ - which are key to our empirical analysis — may be less problematic.

Most importantly, the German SOEP data also provide another, more standard, way to estimate our model. In this case, $M_{t-1}$ represents the father's average gross monthly labour income, and $M_{t}^{j}$ is the labour income of the child. ${ }^{15}$ Thus, the same sort of measurement issues arise, although some of the key determinants of bias, such as the ratios $a_{1} / b_{1 j}$ and $b_{1 m} / b_{1 f}$ and the size of $\operatorname{var}\left(\varepsilon_{t-1}\right)$, may differ in comparison to using the Treiman score measure.

\section{Data}

\footnotetext{
${ }^{14}$ Goldthorpe and Hope (1974) do not consider this issue explicitly. However, they describe (see their chapter 6) some of the problems that are relevant in collecting and coding occupational data, which in turn are of some importance to apply their scale. In particular, "uncertainty arising from incomplete occupation descriptions can be resolved only by the invention of ad hoc rules" (p. 69) over and above those already embodied in the HG scale. To the extent that such measures are used, the new HG scale therefore may not be expected to reflect the occupational prestige that it originally intended to capture. The emergence (disappearing) of a new (old) occupation can presumably generate the same sort of uncertainty.

${ }^{15}$ Children's incomes are measured in the last survey period when we observe positive labour income. In the case of women we also restrict the sample to those in full-time employment (see subsection 3.2).
} 


\subsection{The BHPS sample ${ }^{16}$}

For Britain, we perform our estimation on 2,046 daughters and 2,151 sons who have valid information on their own, their father's and partner's HG scores. In Figure 1 we plot the HG index distributions for fathers, fathers-in-law and sons (panel A), or daughters (panel B). The child distributions are bimodal, but more clearly so in the case of daughters. The spike on the left (which corresponds to lower prestige) is also more pronounced for daughters. This suggests that women are more concentrated in low-prestige occupations and can be found in fewer occupations than men. The figure shows a mean displacement, in that the distributions for fathers and fathers-in-law are skewed to the right while the child distributions are bimodal, or (as in the case of sons) even skewed to the left (the skewness coefficient is about -0.043 ). This displacement is associated with an increase in average prestige over time as well as with higher status dispersion (means and standard deviations are reported in Table 1). So the HG index distribution is not stable across generations and, in particular, low-prestige occupations that characterised the fathers' distribution have increasingly disappeared from the child distributions.

\subsection{The German SOEP samples ${ }^{17}$}

For Germany, we use two different samples. The first, which is similar to that drawn from the BHPS, consists of children for whom we have valid information on their father's, their partner's as well as their own Treiman scores. This sample includes 2,213 daughters and 2,670 sons. Figure 2 depicts the Treiman index distributions for fathers, fathers-in-law and sons (panel A), or daughters (panel B). As in the case of Britain, the child distributions are bimodal, although — differently from Britain — most of the distributions are concentrated in

\footnotetext{
${ }^{16}$ Detailed information about the BHPS is at http://www.iser.essex.ac.uk/bhps/docs.

${ }^{17}$ For further information about the SOEP see http:/www.diw.de/english/sop/service/dtc/index.html.
} 
the centre. A smaller spike for daughters is observed at the bottom end of the distribution, while for sons it is observed at the top end, suggesting again that more women than men are concentrated in low-prestige occupations. The Treiman score distributions for fathers and fathers-in-law are similar in both panels. In line with the results for Britain, the figures show a mean displacement across generations, so that the density at higher scores is more pronounced for children in comparison to their fathers and fathers-in-law. For sons, this is particular true for Treiman scores above 50, whereas for daughters it is the case for scores between 45 and 60. Table 1 (upper panel) shows that this displacement is associated with both an increased average level and an increased dispersion in occupational prestige across generations in Germany.

The second sample consists of 242 daughters and 537 sons from original SOEP households who have cohabitated with their partners at least one year during the panel years. We restrict the analysis to a cohort of children born between 1962 and 1977 for whom we have information about their own, their fathers' as well as their partners' monthly labour earnings. Children's and their partners' earnings are observed at ages of at least 25 and are measured in the last survey period we observe positive values. Income data at younger ages would provide noisy information on long-run economic status (for a similar sample selection, see Chadwick and Solon, 2002). Father's self-reported earnings are ten-year averages over the 1984-1993 period to reduce the bias induced by transitory income fluctuations on the intergenerational elasticities (Solon, 1992; Zimmerman, 1992). ${ }^{18}$ Daughters' and son's partners' incomes are full-time earnings. ${ }^{19}$ Summary statistics of this sample are in the bottom panel of Table 1.

\footnotetext{
${ }^{18}$ Yearly observations for which earnings are non-positive or missing are excluded from the analysis. Additional analyses based on father's earnings averaged over different years (e.g., 1984-1989) produced similar results to those reported in Section 5. Similarly, different restrictions on the year of birth of the child led to comparable estimates to those discussed later on. For conciseness, these results are not shown.

19 This selection guarantees a cleaner comparison between women and men. In addition, part-time earnings for the young women in our sample are likely to be noisy measures of permanent economic status.
} 


\section{Statistical methods}

When using the occupational prestige indices, the estimators $\hat{\beta}_{1}$ and $\hat{\delta}_{1}$ are equivalent to substituting the scale data for permanent incomes in equations (4) and (5) and estimating them using ordinary least squares (OLS) regressions. To align the age-status profiles across generations, age and age squared of the child, or child's partner, are also included as regressors in the estimation. Table 1 indicates that the sample mean age is about 40 for sons and 38-39 for daughters. However, father's age is not available in the BHPS, so it cannot be included. ${ }^{20}$

As illustrated in (10) and (11) and discussed above, the OLS estimates of $\beta_{1}$ and $\delta_{1}$ are biased because of errors-in-variables (as captured by $\operatorname{var}\left(\varepsilon_{t-1}\right)$ ) and because of potentially different links between permanent income and prestige scores for fathers and children (as captured by the ratio $a_{1} / b_{1 j}$ ). Like many other studies of intergenerational mobility, we try to reduce the errors-in-variables bias by measuring child's permanent income with a multiyear average of the child prestige index over the survey period (denoted by $\bar{M}_{t}$ and $\bar{M}_{t}^{p}$ ). That is, in place of equation (9), we have:

$$
y_{t}^{j}=b_{0 j}+b_{1 j} \bar{M}_{t}^{j}+\bar{\varepsilon}_{t j}
$$

where $j=m, f$. We expect $\operatorname{var}\left(\bar{\varepsilon}_{t j}\right)<\operatorname{var}\left(\varepsilon_{t j}\right)$. Re-writing (4) as $y_{t-1}=-\left(\beta_{0}+u_{1 t}\right) \beta_{1}^{-1}+y_{t} \beta_{1}^{-1}$ suggests a "reverse regression" estimator for $\beta_{1}$ and $\delta_{1}$. For sons, $\hat{\beta}_{1}^{R}=\frac{\operatorname{var}\left(\bar{M}_{t}^{m}\right)}{\operatorname{cov}\left(M_{t-1}, \bar{M}_{t}^{m}\right)}$, and

\footnotetext{
${ }^{20}$ In the SOEP, however, respondents report the date of birth of their parents. We can therefore include father's age and age squared in our regressions. The results obtained from such regressions are virtually identical to those reported in Table 3. To keep comparability with the BHPS analysis, however, the next section only shows estimates that exclude father's age.
} 
analogously $\hat{\delta}_{1}^{R}=\frac{\operatorname{var}\left(\bar{M}_{t}^{f}\right)}{\operatorname{cov}\left(M_{t-1}, \bar{M}_{t}^{f}\right)}$. Then, using the measurement model in equations (8) and

(13) and equations (4) and (5), it follows that

$$
p \lim \hat{\beta}_{1}^{R}=\beta_{1}\left[\frac{a_{1}}{b_{1 m}}\right]\left[\frac{\operatorname{var}\left(y_{t}^{m}\right)+\operatorname{var}\left(\bar{\varepsilon}_{t m}\right)}{\operatorname{var}\left(y_{t}^{m}\right)-\operatorname{var}\left(u_{1 t}\right)}\right],
$$

and

$$
\begin{aligned}
& p \lim \hat{\delta}_{1}^{R}=\delta_{1}\left[\frac{a_{1}}{b_{1 f}}\right]\left[\frac{\operatorname{var}\left(y_{t}^{f}\right)+\operatorname{var}\left(\bar{\varepsilon}_{t f}\right)}{\operatorname{var}\left(y_{t}^{f}\right)-\operatorname{var}\left(u_{2 t}\right)}\right] . \\
& \text { Since } \frac{\operatorname{var}\left(y_{t}^{m}\right)+\operatorname{var}\left(\bar{\varepsilon}_{t m}\right)}{\operatorname{var}\left(y_{t}^{m}\right)-\operatorname{var}\left(u_{1 t}\right)}>1 \text {, the reverse regression estimator } \hat{\beta}_{1}^{R} \text { tends to be biased }
\end{aligned}
$$
upwards, even if the ratio $a_{1} / b_{1 m}$ is unity. But the bias will be smaller if $\operatorname{var}\left(\bar{\varepsilon}_{t m}\right)$ is smaller, and if $\operatorname{var}\left(u_{1 t}\right) / \operatorname{var}\left(y_{t}^{m}\right)$ is smaller. Similar arguments apply to $\hat{\delta}_{1}^{R}$. Note that the measurement error in $M_{t-1}$, which we cannot reduce by taking multiyear averages, does not affect these estimators.

The augmented OLS regressions that produce multivariate estimators analogous to $\hat{\beta}_{1}^{R}$ and $\hat{\delta}_{1}^{R}$ include multiyear averages of child's age and age squared and multiyear averages of partner's age and age squared, respectively. We label this method "OLS-reverse". If the ratios $a_{1} / b_{1 j}$ are unity, then the OLS and OLS-reverse estimates should produce lower and upper bound estimates of $\beta_{1}\left(\delta_{1}\right)$, respectively. In contrast to the consistent estimate of $\mu$ based on the OLS estimates when $b_{1 m}=b_{1 f}$, the estimate of $\mu$ based on the OLS-reverse estimates is only consistent under special conditions. In fact, in addition to $b_{1 m}=b_{1 f}$, it must also be the case that $\frac{\operatorname{var}\left(y_{t}^{m}\right)+\operatorname{var}\left(\bar{\varepsilon}_{t m}\right)}{\operatorname{var}\left(y_{t}^{m}\right)-\operatorname{var}\left(u_{1 t}\right)}=\frac{\operatorname{var}\left(y_{t}^{f}\right)+\operatorname{var}\left(\bar{\varepsilon}_{t f}\right)}{\operatorname{var}\left(y_{t}^{f}\right)-\operatorname{var}\left(u_{2 t}\right)}$.

We may over- or under-estimate the true value of $\mu$ using the OLS estimates, depending on how the links between permanent income and prestige scores differ between 
partners. To assess the severity of this problem, we estimate an approximation to equation (9) separately for husbands and wives and under two alternative specifications. The first specification uses contemporaneous total personal income or earnings and scores, and the second uses their corresponding multiyear averages. The results, which are robust to the inclusion of quadratic polynomials in age in both specifications, are shown in Table 2. The estimated ratio $b_{1 m} / b_{1 f}$ is not significantly different from unity for Britain when we use annual incomes, although it slightly exceeds unity when we use earnings. This suggests that the OLS estimates are likely to yield consistent estimates of $\mu$ for Britain. But for Germany, this ratio is well in excess of one, thereby suggesting that the estimate of $\mu$ for Germany is upward-biased.

Table 2 also presents the least-squares estimates of $a_{1}$ from equation (8). Because we do not have information on parents' or fathers' incomes in the BHPS, such estimates have been obtained from a subsample of working fathers who report valid information on incomes and occupation (and therefore HG scores) and were born before $1950 .^{21}$ Both regressions show that the estimated ratios $a_{1} / b_{1 m}$ and $a_{1} / b_{1 f}$ are close to one when we use annual incomes, but slightly larger than one when we use monthly earnings. This suggests that the bias in the estimates of $\beta_{1}$ and $\delta_{1}$ due to different links between incomes and HG scores of parents and offspring may be small for Britain. This implies that the OLS estimates are biased downward and the OLS-reverse estimates are biased upward (see equations (10) and (11) and (14) and (15), respectively). For Germany, $a_{1} / b_{1 m}$ is close to unity, but $a_{1} / b_{1 f}$ is well in excess of one. The latter suggests that the OLS estimate of $\delta_{1}$ for sons ( $\beta_{1}$ for daughters) may be biasedupward, counteracting the measurement error bias.

An important, often ignored, issue for the estimation of intergenerational mobility parameters is that labour market participation decisions are not random, especially in the case

\footnotetext{
${ }^{21}$ Similar results for Britain were found for a sample of working fathers born between 1940 and 1960.
} 
of women. ${ }^{22}$ For daughters, we account for this sample selection issue using the semiparametric two-step procedure described in Vella (1998), which is based on standard exclusion restrictions. ${ }^{23}$ Although the selectivity correction terms are in general statistically significant, our main results in both countries do not change if such terms are excluded from the analysis.

\section{Results}

Table 3 contains the OLS and OLS-reverse estimates of $\beta_{1}$ and $\delta_{1}$ for sons and daughters separately. The OLS estimate of $\beta_{1}$ is 0.31 for sons and 0.26 for daughters in Britain, and similar at 0.33 and 0.25 for Germany (first two columns of Table 3). The estimate of $\delta_{1}$ is lower in both countries: about 0.20 for both sexes in Britain, and 0.26 and 0.20 for male and female partners respectively in Germany. As already discussed, these estimates are probably biased downwards. ${ }^{24}$ As expected, the OLS-reverse method (shown in the last two columns of Table 3) produces much higher values in Britain, rising to 0.44 and 0.40 in the case of $\beta_{1}$ and to 0.29 and 0.27 in the case of $\delta_{1}{ }^{25}$ In Germany, the OLS-reverse estimates are similar to the OLS ones.

\footnotetext{
${ }^{22}$ Common practice in most of the existing studies has been to exclude all records of data where parents or children report no earnings or income (because, for example, they were unemployed at the time of the survey). Two exceptions are the studies by Couch and Lillard (1998) and Minicozzi (2003). Both studies, which interestingly consider only men, conclude that there exists an important role for assumptions on labour market selection in identifying intergenerational income mobility, but their evidence is mixed. Couch and Lillard assign one dollar of income to individuals who have a valid report of no earnings, and find that more selected samples lead to higher intergenerational correlations between sons' and fathers' incomes. Minicozzi uses another method and estimates different Manski-type bounds around sons' income. Contrary to Couch and Lillard, she finds that dropping both unemployed and part-time employed sons leads to a higher degree of mobility than if part-time employed sons had been included.

${ }^{23}$ In particular, all regressions for daughters include a cubic polynomial of the single index function that determines the selection into employment. The variables included in this selection equation are listed in the note to Table 3 .

${ }^{24}$ Interestingly, in spite of the fact that we use a different measure of status, our OLS estimates of $\beta_{1}$ are close to (and perhaps higher than) those shown in Atkinson et al. (1983) - when they use net family income as their variable of interest - and to those reported in Blanden et al. (2003), where the log of children's earnings are regressed on the log of parental income. However in contrast to Atkinson et al. (1983) for Britain, our estimates of $\delta_{1}$ are always smaller than those of $\beta_{1}$.

${ }^{25}$ Given the estimates of the $a_{1} / b_{1 j}$ ratios of about unity in Table 2, the two sets of estimates are likely to be lower and upper bounds, respectively, for Britain.
} 
For Germany, we also have estimates based on average earnings. Compared to the estimates based on occupational prestige scores, these provide higher estimates of both $\beta_{1}$ and $\delta_{1}$ for sons (about 0.4 and 0.33 respectively), and lower ones for daughters (around 0.15 for both parameters). Our $\beta_{1}$ estimates for sons are comparable to those reported by Couch and Dunn (1997, see their Table 2 and discussion in p. 220). Instead, we cannot compare our estimates for daughters to those presented in Couch and Dunn (1997), because they use mother-daughter pairs rather than father-daughter pairs. Our estimates however are substantially greater than theirs, which are typically negative. In addition to our use of fatherdaughter pairs, this difference may also be driven by our selection on full-time female workers.

The OLS-reverse $\beta_{1}$ estimates for British sons and the earnings-based $\beta_{1}$ estimates for German sons are close to the 0.4 "consensus" estimates found in the recent literature on sons' intergenerational earnings mobility (Solon, 1999). The British OLS-reverse estimates for daughters are also close to the 0.4 mark and are comparable to those found by Chadwick and Solon (2002). The German estimates for daughters are instead lower, especially those based on earnings. This may be due to occupational segregation which restricts German women to occupations with relatively lower levels of prestige and earnings in comparison to men (Rubery et al., 1999). It may also be due to the fact that the women in the earnings-based sample are young (on average, 8 years younger than those in the score-based sample) and, despite our selection on full-timers, their earnings may not be a good measure of long-run economic status because of the sizeable wage penalties associated with child births and early career interruptions (Kunze and Ejrnaes, 2004).

One of the main goals of our study is to use these estimates to explore the role of assortative mating in intergenerational mobility of married sons and daughters. The estimated values of $b_{1 m} / b_{1 f}$ reported in Table 2 strongly suggest that our estimate of $\mu$ from the OLS 
estimates should be consistent for Britain. In fact the implied values of $\mu$ in Table 3 are stable across estimation procedures, suggesting that the component of intergenerational mobility that is attributable to assortative mating may be fairly confidently estimated regardless of the method used for estimating the $\beta_{1}$ and $\delta_{1}$ parameters. The estimated value of $\mu$ is 0.39 for men and varies between 0.40 and 0.43 for women. For Germany, there is also consensus across estimation procedures, including the one using average earnings. The estimated value of $\mu$ for German sons and daughters ranges between 0.43 and 0.50 . Because the values of $b_{1 m} / b_{1 f}$ in Table 2 are significantly greater than unity for Germany, our corresponding estimates of $\mu$ might be biased upward.

For both men and women in both countries, therefore, 40-50 percent of the covariance between their own permanent family income and that of their parents can be attributed to sorting in the marriage market. As indicated by their (bootstrap) standard errors, these proportions are usually precisely estimated, although less so when using average earnings for Germany, in part due to smaller samples. With 40-50 percent of one's social position attributable to the process of who marries whom, assortative mating appears to be a major factor in the intergenerational transmission of economic status.

Under the assumption that $\gamma_{1}=\gamma_{2}$, we can also retrieve the degree of assortative mating with respect to human capital, $\alpha_{1}$. Table 3 shows that in Britain $\hat{\alpha}_{1}$ is about 0.65 for sons and varies between 0.68 and 0.76 for daughters. The estimates are higher in Germany, but not very precisely estimated when using average earnings (especially in the case of daughters). Our model uses a broad concept of (unobservable) human capital. The British estimates, especially those for sons, are very close to the estimates in Kremer (1997), who reports that the spouse correlations in years of education are between 0.62 and 0.65 . The figures for Germany and for British daughters, instead, seem high relative to the available estimates that document the process of assortative mating (Epstein and Guttman, 1984), 
although none of these estimates is based on one broad measure of human capital. For Germany, the estimates of $\alpha_{1}$, which are likely to be upward biased (as indicated by the values of $b_{1 m} / b_{1 f}$ in Table 2), could also reflect the fact that the school system selects pupils into distinct, highly separated educational tracks very early on in life (Jenkins and Schluter, 2002). This in turn may affect the pool of potential spouses that people meet and drive up the educational correlation between partners (Mare, 1991). ${ }^{26}$

Another approach to the issue of gauging the role of assortative mating in the transmission of economic status across generations was taken by Chadwick and Solon (2002). We can use this approach only for Germany. We replicate their study, and come to the same conclusion regarding the importance of assortative mating that they came to for the United States. The results are provided in Table 4 (the summary statistics for this sample are reported in Appendix Table A1). ${ }^{27}$ The estimate of the elasticity of offspring's own earnings with respect to the parents' income for daughters is about half the size of that found by Chadwick and Solon, and the estimated elasticity for sons is about one-third the size. But, similar to them, the statistically insignificant coefficients associated with the log of the partner's share of combined earnings in Table 4 indicate that the elasticity of spouses' earnings with respect to the parents' income is not significantly different from the elasticity of offspring's own earnings with respect to the parents' income. Thus, assortative mating plays a crucial role in intergenerational economic mobility.

\footnotetext{
${ }^{26}$ Although years of education and earnings do not straightforwardly correspond to the concepts of human capital and permanent income in the context of the model of Section 1, several empirical studies provide evidence of wage returns to education that are larger for women than for men both in Germany and in Britain (Lauer and Steiner, 2000; Harmon et al., 2001; Walker and Zhu, 2001). If this is the case also among partners, such results imply that our estimates of $\alpha$ for daughters should increase by about 25 percent in both countries.

${ }^{27}$ Due to data availability, our sample selection differs from that used by Chadwick and Solon (2002) in a number of ways. In particular, our sample consists of a younger cohort of children who were born between 1962 and 1977. In our analysis, children's earnings are measured in the last survey period we observe positive values (rather than one specific year of the survey). Moreover, father's labour earnings are ten-year averages over the years 1984-1993 (although most of our results hold if we average over a shorter time period). To maximise sample size, our analysis includes all children present in a household rather than the oldest siblings (again, retaining only the oldest siblings does not change our main findings) as well as all cases with imputed earnings. Finally, as in the previous analysis, we only include daughters in full-time employment.
} 


\section{Conclusions}

This paper makes two contributions to the intergenerational mobility literature. The first is to estimate economic mobility for sons and daughters in a framework that highlights the role played by assortative mating. Using data from the British Household Panel Survey and the German Socio-Economic Panel, we find that assortative mating plays an important role. On average about 40-50 percent of the covariance between parents' and own family permanent income can be attributed to assortative mating. This effect is driven by strong spouse correlations in human capital.

On the methodological front, we find that using occupational prestige scores of fathers and offspring as a predictor of permanent income produces similar results to those using average earnings data in Germany. Therefore, this method can be employed in countries or datasets that do not have sufficient information on earnings of parents and their offspring, because household surveys often collect information on a respondent's father's occupation (but not earnings). 


\section{References}

Atkinson, Anthony B., Maynard, Alan K., and Trinder, Christopher G. 1983. Parents and Children: Incomes in Two Generations. London: Heinemann.

Becker, Gary S. 1989. "On the Economics of the Family: Reply to a Skeptic." American Economic Review, 79(3), 514-18.

Becker, Gary S. 1991. A Treatise on the Family. Cambridge, Mass.: Cambridge University Press.

Becker, Gary S., and Tomes, Nigel. 1979. "An Equilibrium Theory of the Distribution of Income and Intergenerational Mobility." Journal of Political Economy, 87(6), 115389.

Becker, Gary S., and Tomes, Nigel. 1986. "Human Capital and the Rise and Fall of Families." Journal of Labor Economics, 4, S1-S39.

Behrman, Jere R., and Taubman, Paul. 1990. "The Intergenerational Correlation Between Children's Adult Earnings and Their Parents' Income: Results from the Michigan Panel Survey of Income Dynamics." Review of Income and Wealth, 36(2), 115-27.

Blanden, Jo, Goodman, Alissa, Gregg, Paul, and Machin, Stephen. 2003. "Changes in Intergenerational Mobility in Britain." In Generational Income Mobility in North America and Europe, edited by Miles Corak. Cambridge: Cambridge University Press (forthcoming).

Chadwick, Laura, and Solon, Gary. 2002. "Intergenerational Income Mobility Among Daughters." American Economic Review, 92(1), 335-44.

Couch, Kenneth A., and Dunn, Thomas A. 1997. "Intergenerational Correlations in Labor Market Status: A Comparison of the United States and Germany." Journal of Human Resources, 22(1), 210-32.

Couch, Kenneth A. and Lillard, Dean R. 1998. "Sample Selection Rules and the Intergenerational Correlation of Earnings." Labour Economics, 5, 313-329.

Dearden, Lorraine, Machin, Stephen, and Reed, Howard. 1997. "Intergenerational Mobility in Britain.” Economic Journal, 107, 47-66.

Epstein, Elizabeth, and Guttman, Ruth. 1984."Mate Selection in Man: Evidence, Theory, and Outcome." Social Biology, 31(3-4), 243-78.

Ganzeboom, Harry B. G. and Treiman, Donald. 1996. "Internationally comparable Measures of Occupational Status for the 1988 International Standard Classification of Occupations." Social Science Research, 25, 201-239.

Goldberger, Arthur S. 1989. "Economic and Mechanical Models of Intergenerational Transmission." American Economic Review, 79(3), 504-13. 
Goldthorpe, John H., and Hope, Keith. 1974. The Social Grading of Occupations: A New Approach and Scale. Oxford: Clarendon Press.

Goody, Jack. 1983. The Development of the Family and Marriage in Europe. Cambridge: Cambridge University Press.

Hamilton, Cicely M. 1912. Marriage as a Trade. London: Chapman and Hall.

Harmon, Colm, Westergaard-Nielsen, Niels, and Walker, Ian. 2001. Education and Earnings across Europe. Cheltenham: Edward Elgar.

Jenkins, Stephen P., Schluter, Christian. 2002.'The Effect of Family Income During Childhood on Later-Life Attainment: Evidence from Germany." ISER Working Paper No. 2002-20, University of Essex, Colchester, October.

Kalmijn, Matthijs. 1994. "Assortative Mating by Cultural and Economic Occupational Status." American Journal of Sociology, 100(2), 422-52.

Kremer, Michael. 1997. "How Much Does Sorting Increase Inequality?” Quarterly Journal of Economics, 112(1), 115-39.

Kunze, Astrid, and Ejrnaes, Mette. 2004. "Wage Dips and Drops around First Births." IZA Discussion Paper No. 1011, IZA Bonn, February.

Lam, David. 1988. "Marriage Markets and Assortative Mating with Household Public Goods: Theoretical Results and Empirical Implications." Journal of Human Resources, 23(4), 462-87.

Lam, David, and Schoeni, Robert F. 1993. "Effects of Family Background on Earnings and Returns to Schooling: Evidence from Brazil." Journal of Political Economy, 101(4), 710-40.

Lam, David, and Schoeni, Robert, F. 1994. "Family Ties and Labor Market in the United States and Brazil." Journal of Human Resources, 29(4), 1235-58.

Lauer. Charlotte, and Steiner, Viktor. 2000. "Returns to Education in West Germany." ZEW Discussion Paper No. 00-04, ZEW, Mannheim.

Lillard, Lee A., and Kilburn, M. Rebecca. 1995. "Intergenerational Earnings Links: Sons and Daughters.” Mimeo, RAND. Santa Monica, CA.

Loury, Glenn C. 1981. "Intergenerational Transfers and the Distribution of Earnings." Econometrica, 49(4), 843-67.

Mare, Robert D. 1991. "Five Decades of Educational Assortative Mating." American Sociological Review, 56(1), 15-32.

Minicozzi, Alexandra L. 2003. "Estimation of Sons' Intergenerational Earnings Mobility in the Presence of Censoring." Journal of Applied Econometrics, 18, 291-314. 
Mulligan, Casey B. 1999. "Galton vs. the Human Capital Approach to Inheritance.” Journal of Political Economy, 107(6), Part 2, S184-S224.

Nickell, Stephen. 1982. "The Determinants of Occupational Success in Britain." Review of Economic Studies, 49, 43-53.

Phelps Brown, Henry E. 1977. The Inequality of Pay. Oxford: Oxford University Press.

Rubery, Jill, Smith, Mark, and Fagan, Colette. 1999. Women's Employment in Europe. London: Routledge.

Slater, Eliot, and Woodside, Moya. 1951. Patterns of Marriage: A Study of Marriage Relationships in the Urban Working Classes. London: Cassell.

Solon, Gary R. 1999. "Intergenerational Mobility in the Labour Market." In Handbook of Labor Economics, Volume 3A, edited by Orley Ashenfelter and David Card. Amsterdam: North-Holland, 1761-1800.

Stone, Lawrence. 1977. The Family, Sex and Marriage in England 1500-1800. London: Weidenfeld and Nicolson.

Thomas, Duncan. 1994. "Like Father, Like Son; Like Mother, Like Daughter: Parental Resources and Child Height." Journal of Human Resources, 29(4), 950-88.

Vella, Francis. 1998. "Estimating Models with Sample Selection Bias: A Survey." Journal of Human Resources, 33(1), 127-69.

Walker, Ian, and Zhu, Yu. 2001. The Returns to Education: Evidence from the Labour Force Surveys. Department for Education and Skills, Research Report No. 313, HMSO, November.

Zimmerman, David J. 1992. "Regression Toward Mediocrity in Economic Stature." American Economic Review, 82(3), 409-29. 
Figure 1

Kernel density estimates of the child, father and father-in-law's HG scores distributions by child gender in the BHPS

A. Sons

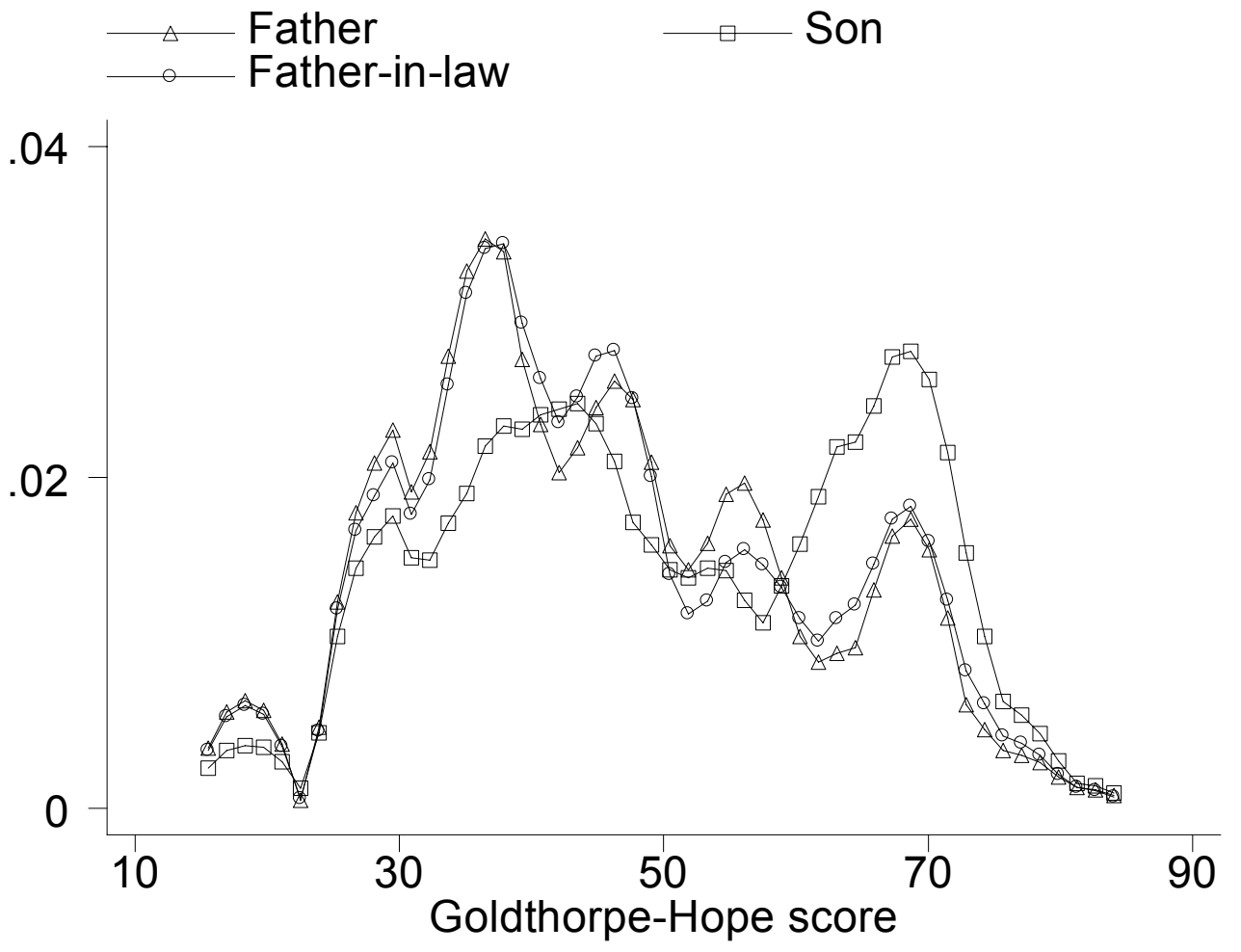

B. Daughters

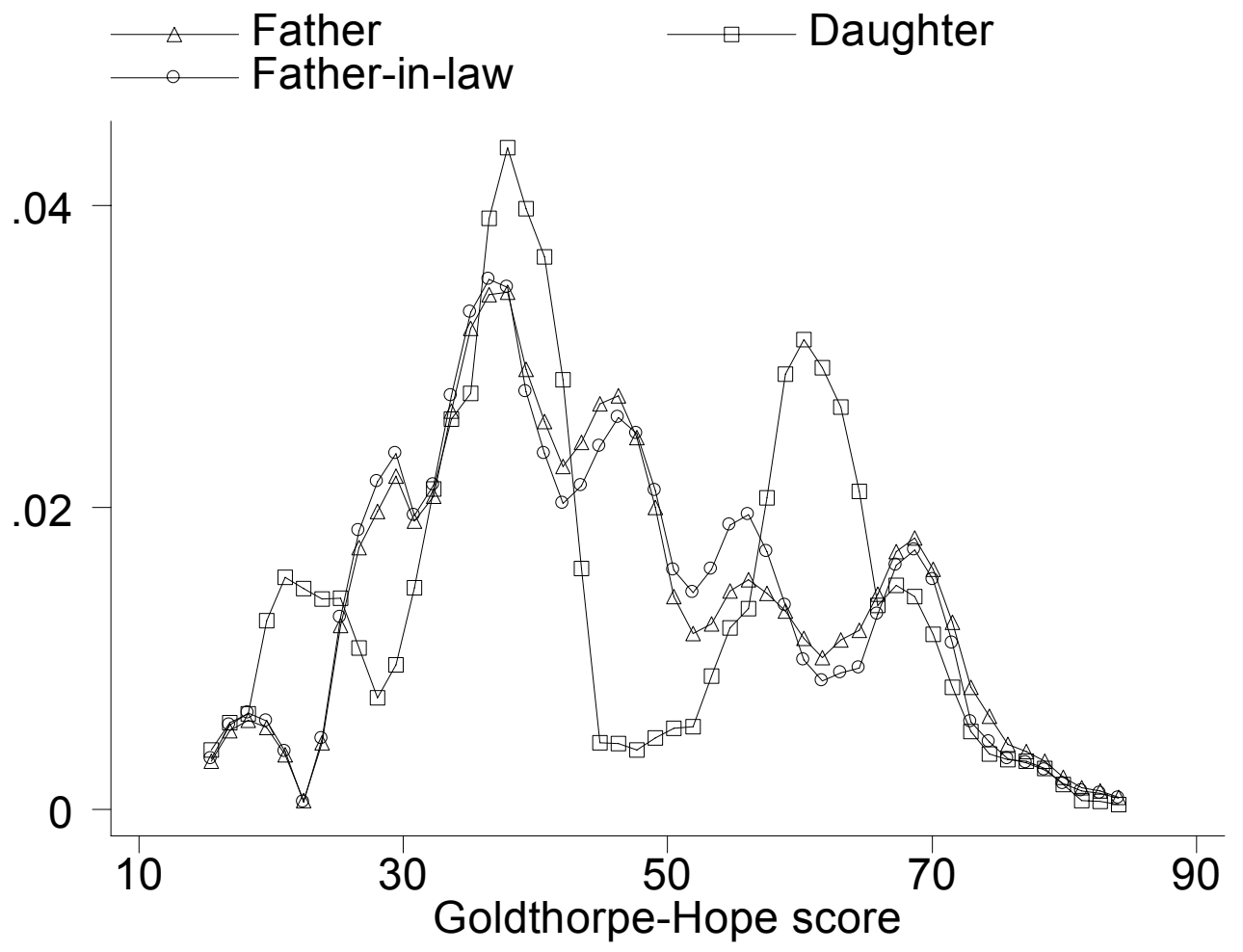


Figure 2

Kernel density estimates of the child, father and father-in-law's Treiman scores distributions by child gender in the SOEP

A. Sons

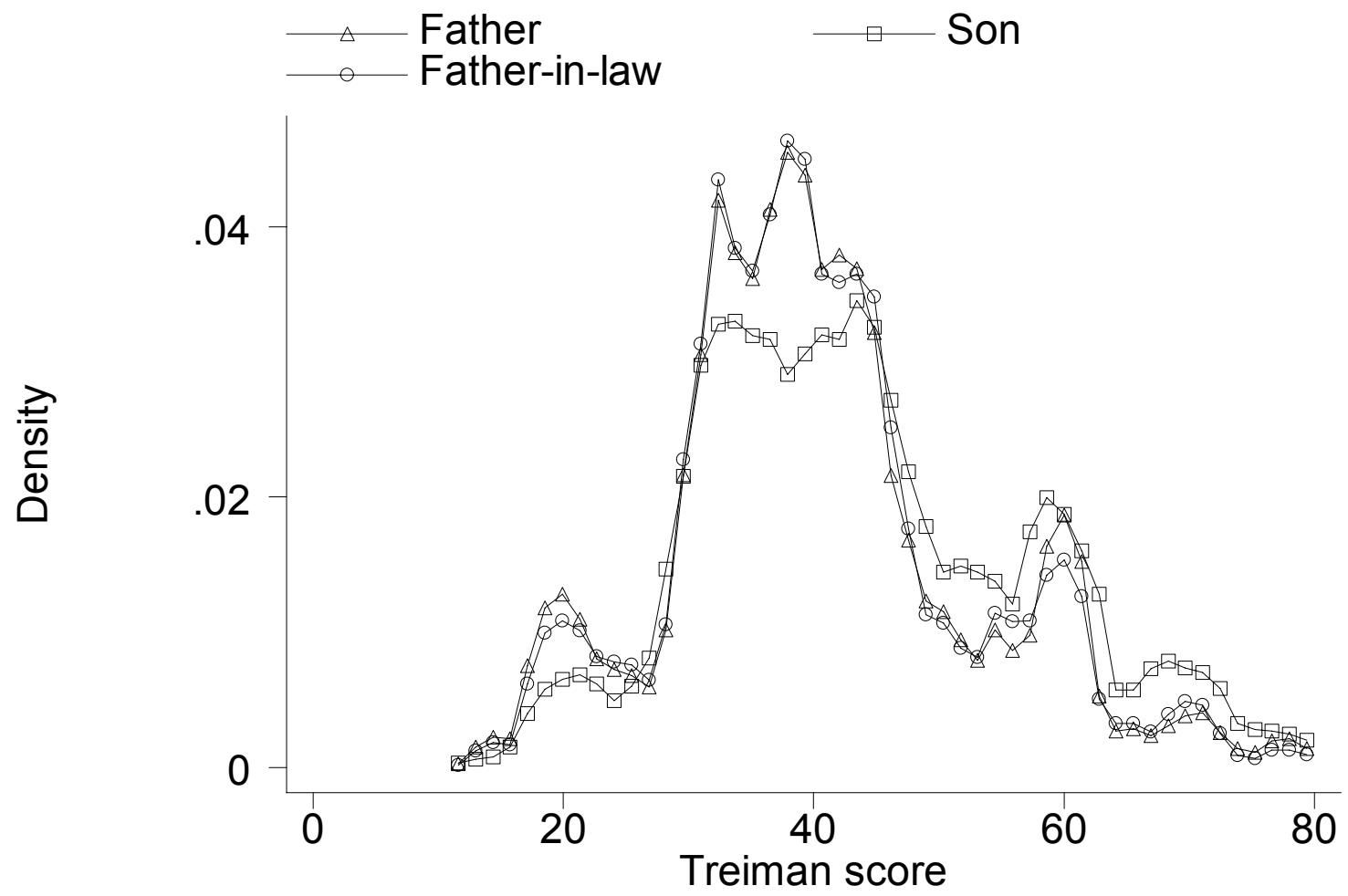

B. Daughters

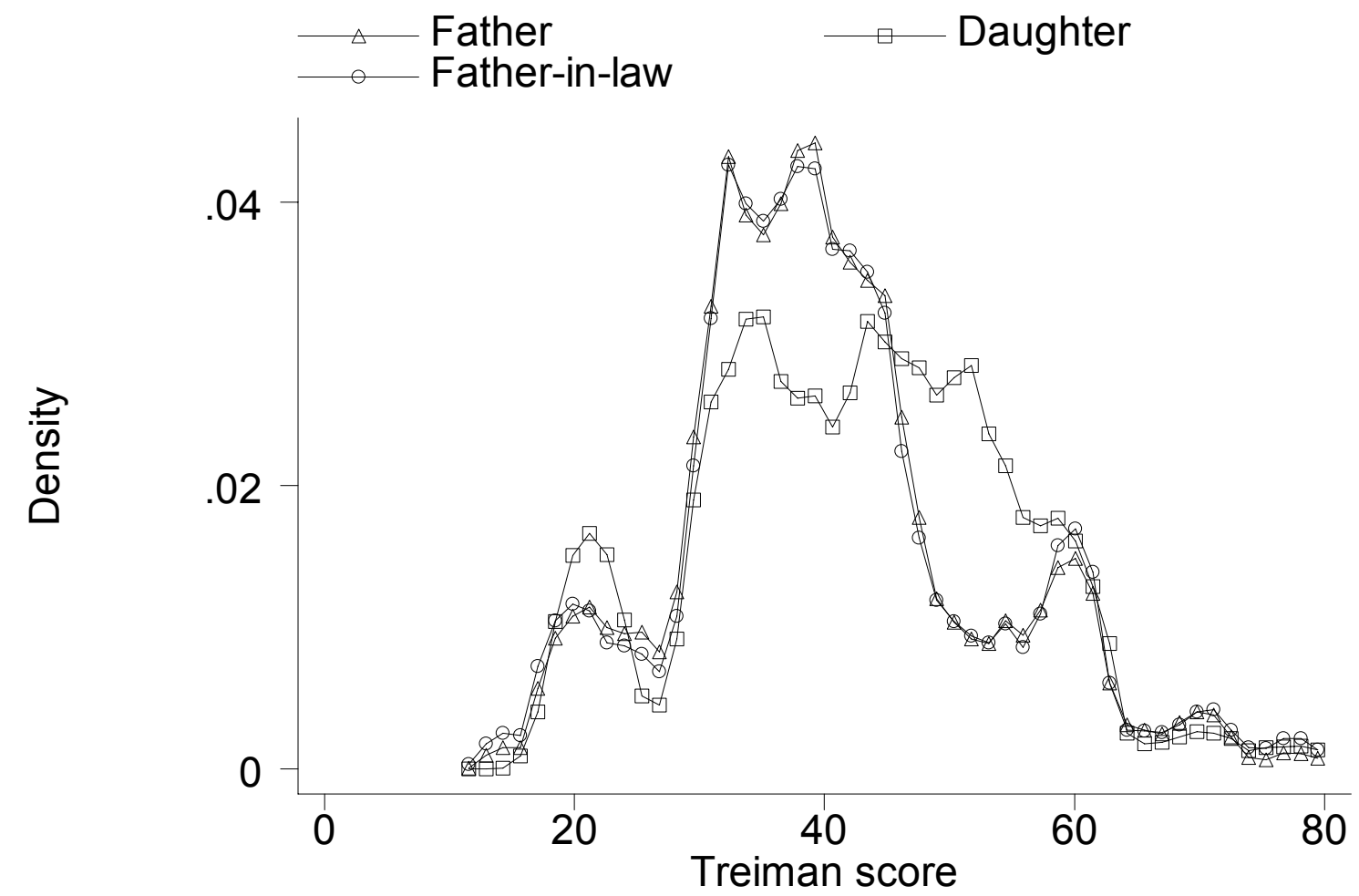


Table 1

Descriptive statistics

\begin{tabular}{|c|c|c|c|c|}
\hline \multirow[b]{2}{*}{ Variable } & \multicolumn{2}{|c|}{ BHPS } & \multicolumn{2}{|c|}{ SOEP } \\
\hline & Sons & Daughters & Sons & Daughters \\
\hline \multicolumn{5}{|l|}{ Occupational scores: } \\
\hline Child & $\begin{array}{l}51.238 \\
(15.238)\end{array}$ & $\begin{array}{l}46.065 \\
(15.608)\end{array}$ & $\begin{array}{c}44.042 \\
(13.092)\end{array}$ & $\begin{array}{c}42.690 \\
(12.363)\end{array}$ \\
\hline Father & $\begin{array}{l}45.969 \\
(14.757)\end{array}$ & $\begin{array}{l}46.694 \\
(14.939)\end{array}$ & $\begin{array}{c}40.652 \\
(12.139)\end{array}$ & $\begin{array}{c}40.258 \\
(11.654)\end{array}$ \\
\hline Father-in-law & $\begin{array}{l}46.621 \\
(14.881)\end{array}$ & $\begin{array}{l}45.467 \\
(14.493)\end{array}$ & $\begin{array}{c}40.638 \\
(11.782)\end{array}$ & $\begin{array}{c}40.558 \\
(12.271)\end{array}$ \\
\hline Child's age & $\begin{array}{l}40.274 \\
(9.607)\end{array}$ & $\begin{array}{l}38.932 \\
(9.742)\end{array}$ & $\begin{array}{c}39.857 \\
(10.734)\end{array}$ & $\begin{array}{l}37.920 \\
(10.660)\end{array}$ \\
\hline $\begin{array}{l}\text { Number of person-wave } \\
\text { observations }\end{array}$ & 12,357 & 10,646 & 9,657 & 7,012 \\
\hline Number of individuals & 2,151 & 2,046 & 2,670 & 2,213 \\
\hline
\end{tabular}

Earnings:

Child

$\begin{array}{ll}2863.34 & 1952.00 \\ (1500.77) & (689.67) \\ 2056.55 & 2673.30 \\ (700.22) & (1370.53) \\ 2388.27 & 2318.54 \\ (1082.49) & (958.86)\end{array}$

Age:

Child

32.76

29.51

(3.72)

Partner

30.35

(3.34)

(3.93)

33.77

Father (average) ${ }^{\mathrm{a}}$

49.69

(3.72)

47.97

(5.97)

Number of individuals

537

242

Number of partners

221

541

Note: In the upper panel, figures are means (standard deviations) computed on the number of person-wave observations. In the lower panel, figures are computed on the number of children and their partners. Scores are the Hope-Goldthorpe score for the BHPS and the Treiman score for the SOEP. Earnings are gross monthly earnings deflated using the Consumer Price Index and are expressed in 2001 Euros. Earnings for women are full-time earnings. Children's and their partners' earnings are measured in the last year we observe positive earnings in the SOEP.

a Averages are computed over all years from 1984 to 1993 for which valid earnings and age information were available. 


\section{Table 2}

The relationships between scores and incomes and earnings for sons and daughters and between scores and family income and earnings for fathers - Estimates of $b_{1 m}, b_{1 f}$, and $a_{1}$ and their ratios

\begin{tabular}{ccccccc}
\hline & & & & $b_{1 m}$ & $a_{1}$ & $\frac{a_{1}}{b_{1 f}}$ \\
\hline BHPS & $b_{1 m}$ & $b_{1 f}$ & $a_{1}$ & & & \\
Incomes: & & & & & & \\
Levels & 369.49 & 359.43 & 365.62 & 1.028 & 0.990 & 1.017 \\
& $(5.61)$ & $(5.16)$ & $(28.62)$ & {$[0.052]$} & {$[0.079]$} & {$[0.110]$} \\
Means & 396.64 & 388.04 & 393.49 & 1.022 & 0.992 & 1.014 \\
& $(9.78)$ & $(8.65)$ & $(18.75)$ & {$[0.069]$} & {$[0.055]$} & {$[0.084]$} \\
& & & & & & \\
Earnings: & & & & & & \\
Levels & 36.37 & 33.29 & 40.36 & 1.093 & 1.110 & 1.212 \\
& $(1.03)$ & $(0.92)$ & $(2.93)$ & {$[0.028]$} & {$[0.032]$} & {$[0.056]$} \\
Means & 39.42 & 35.36 & 42.11 & 1.115 & 1.068 & 1.191 \\
& $(1.87)$ & $(1.59)$ & $(2.04)$ & {$[0.039]$} & {$[0.072]$} & {$[0.089]$} \\
& & & & & & \\
SOEP & & & & & & \\
Earnings: & & & & & & \\
Levels & 46.85 & 30.96 & 50.75 & 1.513 & 1.083 & 1.639 \\
Means & $(1.36)$ & $(0.98)$ & $(2.91)$ & {$[0.027]$} & {$[0.026]$} & {$[0.040]$} \\
& 56.40 & 33.50 & 51.00 & 1.683 & 0.903 & 1.524 \\
& $(1.17)$ & $(0.80)$ & $(1.82)$ & {$[0.069]$} & {$[0.049]$} & {$[0.082]$} \\
& & & & & &
\end{tabular}

Note: The figures for the $b$ and $a$ coefficients are in constant (1999) pounds in the BHPS and in constant (2001) Euros in the SOEP. Numbers in parentheses are estimated standard errors, which are robust to arbitrary form of heteroskedasticity in the case of the "levels" specifications. Numbers in square brackets are bootstrap standard errors, which have been computed after 1,000 replications. Earnings are gross monthly earnings deflated using the Consumer Price Index and are expressed in 1999 Pounds and 2001 Euros. 
Table 3

Estimated intergenerational coefficients, assortative mating contributions, and degree of assortative mating for sons and daughters in the BHPS and the SOEP

\begin{tabular}{|c|c|c|c|c|}
\hline & \multicolumn{2}{|c|}{ OLS } & \multicolumn{2}{|c|}{ OLS-reverse } \\
\hline & Sons & Daughters & Sons & Daughters \\
\hline \multicolumn{5}{|l|}{ BHPS } \\
\hline$\beta_{1}$ & $\begin{array}{l}0.306 \\
(0.019)\end{array}$ & $\begin{array}{l}0.259 \\
(0.021)\end{array}$ & $\begin{array}{l}0.444 \\
(0.035)\end{array}$ & $\begin{array}{l}0.397 \\
(0.046)\end{array}$ \\
\hline$\delta_{1}$ & $\begin{array}{l}0.197 \\
(0.022)\end{array}$ & $\begin{array}{l}0.198 \\
(0.020)\end{array}$ & $\begin{array}{l}0.288 \\
(0.051)\end{array}$ & $\begin{array}{l}0.269 \\
(0.048)\end{array}$ \\
\hline$\mu$ & $\begin{array}{l}0.392 \\
{[0.013]}\end{array}$ & $\begin{array}{l}0.433 \\
{[0.013]}\end{array}$ & $\begin{array}{l}0.393 \\
{[0.018]}\end{array}$ & $\begin{array}{l}0.404 \\
{[0.022]}\end{array}$ \\
\hline$\left.\alpha_{1}\right|_{\gamma_{1}=\gamma_{2}}$ & $\begin{array}{l}0.644 \\
{[0.035]}\end{array}$ & $\begin{array}{l}0.764 \\
{[0.042]}\end{array}$ & $\begin{array}{l}0.649 \\
{[0.029]}\end{array}$ & $\begin{array}{l}0.678 \\
{[0.041]}\end{array}$ \\
\hline Number of observations & 12,357 & 10,646 & 2,151 & 2,046 \\
\hline \multicolumn{5}{|l|}{ SOEP } \\
\hline$\beta_{1}$ & $\begin{array}{l}0.333 \\
(0.022)\end{array}$ & $\begin{array}{l}0.251 \\
(0.024)\end{array}$ & $\begin{array}{l}0.329 \\
(0.020)\end{array}$ & $\begin{array}{l}0.242 \\
(0.021)\end{array}$ \\
\hline$\delta_{1}$ & $\begin{array}{l}0.263 \\
(0.022)\end{array}$ & $\begin{array}{l}0.203 \\
(0.023)\end{array}$ & $\begin{array}{l}0.250 \\
(0.020)\end{array}$ & $\begin{array}{l}0.197 \\
(0.020)\end{array}$ \\
\hline$\mu$ & $\begin{array}{l}0.442 \\
{[0.013]}\end{array}$ & $\begin{array}{l}0.447 \\
{[0.019]}\end{array}$ & $\begin{array}{l}0.432 \\
{[0.026]}\end{array}$ & $\begin{array}{l}0.446 \\
{[0.037]}\end{array}$ \\
\hline$\left.\alpha_{1}\right|_{\gamma_{1}=\gamma_{2}}$ & $\begin{array}{l}0.793 \\
{[0.043]}\end{array}$ & $\begin{array}{l}0.811 \\
{[0.064]}\end{array}$ & $\begin{array}{l}0.763 \\
{[0.080]}\end{array}$ & $\begin{array}{l}0.813 \\
{[0.122]}\end{array}$ \\
\hline Number of observations & 9,657 & 7,012 & 2,670 & 2,213 \\
\hline \multicolumn{5}{|l|}{ SOEP } \\
\hline$\beta_{1}$ & $\begin{array}{c}0.396 \\
(0.078)\end{array}$ & $\begin{array}{c}0.152 \\
(0.054)\end{array}$ & & \\
\hline$\delta_{1}$ & $\begin{array}{c}0.332 \\
(0.065)\end{array}$ & $\begin{array}{c}0.152 \\
(0.042)\end{array}$ & & \\
\hline$\mu$ & $\begin{array}{c}0.455 \\
{[0.068]}\end{array}$ & $\begin{array}{c}0.504 \\
{[0.116]}\end{array}$ & & \\
\hline$\left.\alpha_{1}\right|_{\gamma_{1}=\gamma_{2}}$ & $\begin{array}{c}0.867 \\
{[0.253]}\end{array}$ & $\begin{array}{c}1.189 \\
{[0.917]}\end{array}$ & & \\
\hline Number of individuals & 537 & 242 & & \\
\hline Number of partners & 221 & 541 & & \\
\hline
\end{tabular}


Note: Numbers in parentheses are estimated standard errors. In the OLS regressions, standard errors are HuberWhite corrected for the potential correlation in the disturbances across observations. Numbers in square brackets are bootstrap standard errors, which have been computed after 1,000 replications. The OLS regressions include age and age-squared. The OLS-reverse regressions include the averages of child's age and age squared. For daughters, all regressions are selectivity corrected with a cubic polynomial of the index function from the selection equation. For the BHPS sample, the (probit) equation contains: age, number of dependent children by age groups (five age groups: 0-2, 3-4, 5-11, 12-15, 16-18), and dummy variables for race (4 variables), highest educational achievement (5), marital status, year of first partnership (3), and region (16). For the SOEP sample, the (probit) equation contains: age, number of dependent children by age groups (five age groups: 0-1, 2-4, 5-10, 11-15, 16-18), dummy variable for nationality, highest educational achievement (6), marital status and federal states (16). Earnings for women are full-time earnings. 
Table 4

Estimated intergenerational elasticities for children and their partners

\begin{tabular}{|c|c|c|c|}
\hline Dependent variable & All children & $\begin{array}{c}\text { Children with } \\
\text { positive } \\
\text { combined labour } \\
\text { earnings }\end{array}$ & $\begin{array}{c}\text { Children whose } \\
\text { partners have } \\
\text { positive earnings }\end{array}$ \\
\hline \multicolumn{4}{|l|}{ Sons } \\
\hline Log family income & $\begin{array}{c}0.178 \\
(0.050)\end{array}$ & $\begin{array}{c}0.185 \\
(0.038)\end{array}$ & $\begin{array}{c}0.157 \\
(0.051)\end{array}$ \\
\hline $\begin{array}{l}\text { Log of couple's } \\
\text { combined earnings }\end{array}$ & & $\begin{array}{c}0.163 \\
(0.039)\end{array}$ & $\begin{array}{c}0.148 \\
(0.054)\end{array}$ \\
\hline $\begin{array}{l}\text { Log of partner's } \\
\text { earnings }\end{array}$ & & & $\begin{array}{c}0.048 \\
(0.104)\end{array}$ \\
\hline $\begin{array}{l}\text { Log of partner's share of } \\
\text { combined earnings }\end{array}$ & & & $\begin{array}{l}-0.100 \\
(0.085)\end{array}$ \\
\hline Number of observations & 719 & 713 & 487 \\
\hline \multicolumn{4}{|l|}{ Daughters } \\
\hline Log family income & $\begin{array}{c}0.209 \\
(0.051)\end{array}$ & $\begin{array}{c}0.191 \\
(0.038)\end{array}$ & $\begin{array}{c}0.202 \\
(0.037)\end{array}$ \\
\hline $\begin{array}{l}\text { Log of couple's } \\
\text { combined earnings }\end{array}$ & & $\begin{array}{c}0.173 \\
(0.040)\end{array}$ & $\begin{array}{c}0.198 \\
(0.038)\end{array}$ \\
\hline $\begin{array}{l}\text { Log of partner's } \\
\text { earnings }\end{array}$ & & & $\begin{array}{c}0.201 \\
(0.043)\end{array}$ \\
\hline $\begin{array}{l}\text { Log of partner's share of } \\
\text { combined earnings }\end{array}$ & & & $\begin{array}{c}0.003 \\
(0.029)\end{array}$ \\
\hline Number of observations & 630 & 624 & 606 \\
\hline
\end{tabular}

Note: Coefficients refer to the log income of the household of origin of the child. Child's income and earnings variables are measured in the last year they are observed in the panel. 
Table A1

Descriptive statistics

\begin{tabular}{lcc}
\hline Variable & Sons & Daughters \\
& & \\
\hline \multirow{2}{*}{ Age } & 32.11 & 31.35 \\
& $(4.17)$ & $(4.03)$ \\
Log family income & 10.67 & 10.58 \\
& $(0.55)$ & $(0.59)$ \\
Log combined earnings & 10.62 & 10.55 \\
& $(0.58)$ & $(0.59)$ \\
Partner's log labour income & 9.27 & 10.20 \\
& $(1.07)$ & $(0.68)$ \\
Father's age & 51.08 & 49.86 \\
& $(6.84)$ & $(7.03)$ \\
Parents' average log family income & 10.67 & 10.54 \\
& $(0.51)$ & $(0.66)$ \\
Number of individuals & 487 & 606 \\
\end{tabular}

Note: Figures are means (standard deviations) computed on the number of persons. 